\title{
COGNITIVE FUNCTIONS CHANGES AMONG EGYPTIAN SEWAGE NETWORK WORKERS
}

\author{
By \\ Farahat S. A.* and Kishk N.A.** \\ From \\ * Dep. of Industrial Medicine \& Occupational Diseases, ** Dep. of Neurology, Faculty of Medicine,
} Cairo University

\begin{abstract}
:
Objectives: The current work aimed at investigating the cognitive functions impairment among workers of sewer networks due to exposure to $\mathrm{H} 2 \mathrm{~S}$ and the relation of this impairment ,if any, to the level of H2S exposure biomarker "urinary thiosulfate". Besides, the validity of using Mini Mental State Examination (MMSE) as screening test for cognitive impairment among the exposed workers was tested.
\end{abstract}

Subjects: The work was conducted among 33 sewage network maintenance male workers and a matched unexposed control group $(n=30)$.

Methods: The participants were subjected to clinical neurological history, estimation of urinary thiosulfate, and assessment of cognitive dysfunction by using neurophysiological (simple reaction time, P300 test) and neuropsychological tests (Wechsler Memory Scale) and frontal executive functions tests.

Results: Clinical neurological history revealed significantly higher neurological symptoms (headache, memory defects, lack of concentration) among exposed workers compared to their controls $(\mathrm{P}<0.05)$. Exposed workers had significantly prolonged simple reaction time and delayed P300 latency and showed poor performance of most of neuropsychological tests. Marked elevation of urinary thiosulfate was observed among the exposed workers $(\mathrm{P}<0.001)$ but this elevation was not correlated with the duration of exposure or any of the other measured parameters. Exposed workers had significantly lower mean value of MMSE scoring than that of the controls $(\mathrm{P}<0.001)$.

Conclusion: Exposure to $\mathrm{H} 2 \mathrm{~S}$ among sewer network workers is associated with cognitive impairment which can be screened by applying MMSE as a simple rapid test for hydrogen sulfide occupationally exposed workers.

Key words: hydrogen sulfide, sewer networks ,thiosulfate, MMSE, P300, neuropsychological test, frontal executive functions. 


\section{Introduction:}

Hydrogen Sulphide (H2S) is a highly toxic, colorless gas smelling of rotten eggs. It is used in several industries and is a product of many industrial processes such as oil refining, mining and rayon manufacture (Fenga et al., 2002). Because H2S, is produced through decomposition of organic matter by bacteria, it represents one of the most serious chemical hazards that face sewer workers particularly in confined places such as sewer pipes ( Saad et al., 2003).

Exposure to hydrogen sulfide occurs primarily by inhalation but can also occur by ingestion (contaminated food) and skin (water and air). Once taken into the body, it is rapidly distributed to various organs, including the central nervous system, lungs, liver, muscle. The major metabolic pathway for $\mathrm{H} 2 \mathrm{~S}$ in the body is oxidation of sulfide to sulfate with the latter being excreted in the urine in the form of thiosulfate (EPA, 2003). Hydrogen sulfide and hydrogen cyanide are known to compromise mitochondrial respiration through inhibition of cytochrome $\mathrm{c}$ oxidase and this is generally considered to be their primary mechanism of toxicity. This prevents the utilization of oxygen with an uncoupling of oxidative phosphorylation. Thus, the electron transport chain is disrupted by prevent- ing oxygen from acting as the final electron acceptor and causing blockage of oxidative metabolism, leading to anaerobic metabolism, decreased ATP production with curtailed cellular energy generation, and the generation of lactic acid (Thompson et al., 2003). Nervous and cardiac tissues, which have the highest oxygen demand, are especially sensitive to the disruption of oxidative metabolism. This explains the occurrence of sudden death in case of exposure to high concentration (Yalamanchili and Smith,2008).

Many studies have documented the neurological effects following exposures to non-fatal high concentrations of hydrogen sulfide. These effects may be permanent or persistent and include visual and memory impairment, reduced motor function, slight tremor, ataxia, psychosis, abnormal learning, retention, and motor function, and slight cerebral atrophy (ATSDR,2004) . Kilburn, (2004) reported that sensitive testing showed impaired brain functions among acute $\mathrm{H} 2 \mathrm{~S}$ poisoning survivors who had been unconscious and looked all right after that.

Contrarily, long term effects of occupational exposure to low levels of the gas have not been studied enough. However, (Kilburn, 2001) reported that long term exposure to low concentrations of $\mathrm{H} 2 \mathrm{~S}$ is asso- 
ciated with neuropsychiatric and cognitive dysfunction manifestations, including: fatigue, loss of appetite, irritability, impaired memory, altered mood states, headache and dizziness. However, it is not known if these effects are the result of chronic exposure or due to reoccurring acute exposures.

Therefore, this study aims to investigate the cognitive function changes among sewer network workers (as an example to the chronic occupational exposure to $\mathrm{H} 2 \mathrm{~S}$ ) who do not have history of unconsciousness. In addition, the study investigates the validity of using thiosulfate ( $\mathrm{H} 2 \mathrm{~S}$ exposure biomarker) and Mini Mental State Examination (MMSE) (non-specific cognitive function test ) as screening tests for detection of early cognitive function changes among $\mathrm{H} 2 \mathrm{~S}$ exposed personnel.

\section{Subjects \& Methods:}

\section{Subjects:}

This study was carried out among all the workers involved in maintenance of the sewage network of the districts El Manial, Misr el Kadema, and Kasr El- Aini hospitals $(n=42)$. When the workers were asked to join our research,4 refused and 3 were excluded according to our selection criteria so the study started with 35 male workers. The selection criteria were that, the workers must have been regularly working in sewer networks for at least the preceding 5 years and had no history of unconsciousness in relation to work. After taking medical history and applying clinical examination, additional 2 workers were excluded as they had advanced hepatic diseases.

The workers were responsible for inspection of lines in order to detect any perturbation of the wastewater flow and possible defaults (for example, cracks, leaks) of the duct, the curing of the wastewater lines and the extraction of the sediments. Their frequency of exposure was about 3-4 times/ week. None of the participants used to wear protective masks during work. All of the participants were literate.

The controls were recruited among personnel working in different administrative jobs that do not carry the risk of exposure to hydrogen sulfide gas. The controls were chosen as to be matched with exposed workers regarding age, educational level and socio-economic status. The nature of the study was fully explained to each participant and accordingly oral consent was obtained.

\section{Methods:}

Every participant completed a questionnaire sheet including personal, occupational history. Past history included chronic neurological diseases such as cerebrovas- 
cular stroke, Parkinsonism, intracranial neoplasms, major medical diseases such as renal, hepatic, metabolic disorders, known cardiac disease, other endocrinal disorders and associated collagen vascular disorders. Symptoms suggestive of possible cognitive impairment, namely memory defects, lack of concentration and headache were included in the questionnaire. Each participant was subjected to both general and neurological examination.

\section{Estimation of urinary thiosulfate:}

Thiosulfate is determined in urine according to method described by Sorbo and Ohman (1978).

\section{Neuro-physiological Tests:}

Auditory event - related potentials (P300 component):

Event related potentials (ERP) represent the neural activity generated during cognitive process. P300 recorded in a sound attenuated room (Oddball paradigm). A total of 200 auditory stimuli (bursts) were presented to the ears through earphones. $70 \%$ of tones were $1000 \mathrm{~Hz}$ in frequency (background tones) whereas the remaining 30\% were $2000 \mathrm{~Hz}$ (target tones).

The subject was instructed to press on a button connected to the apparatus as quickly as possible whenever hearing the infrequent tones. These tones were presented randomly intermixed at a rate of $0.5 /$ second. The wave P300 was defined as the most positive point of the average waveform to the target tones after $250 \mathrm{msec}$ and before $600 \mathrm{msec}$. For each subject, P300 latency, P300 amplitude and Reaction Time were obtained to detect any significant abnormality. Latency range of P300 can be found is $250-500$ msec for most adult subjects between 20 and 70 years ( Niedermeyer et al.,1999).

\section{Neuro-psychological Assessment:}

Wechsler Memory Scale-revised (WMS-R) ( Wechsler,1981) :

The Wechsler Memory Scale was for many years the standard tool for the assessment of suspected memory disorders. It consists of 13 subtests. However, in this work, we selected the subtests which assess the visual memory and the logical memory:

\section{Visual memory subtests:}

(a) Figural memory: The maximum score is 10 .

(b) Visual Paired Associates I: Maximum score is 18 .

(c) Visual Reproduction I: Maximum score is 4 . 
The previous 3 tests assess the non verbal working memory.

(d) Digit Span:

Digit forward (Normal: $6 \pm 1$, Bordline or impaired: 4, Defective: 3 )

Digit backward (Normal: $5 \pm 1$, Bordline or impaired: 3, Defective:2)

This test measures attention process and short term auditory verbal (working) memory

\section{Logical Memory Subtest:}

The total scoring of 50 and patient who scores $<25$ is considered to have learning and working memory difficulties. This test examines the verbal memory

\section{B- Frontal executive functions: they were tested by}

\section{Verbal fluency (Benton,1968)}

It assesses the patient's ability to generate responses by having them produced as many words as possible in one minute related to certain category, beginning with the names of foods, then names of animals. It tests for semantic memory. Persons who score $<15$ words on the average scores of foods and animals names were showed to have impairment on this task. Scoring of $<10$ words indicates severe memory defects.

\section{Trail Making A Test (Reitan, 1958)}

score 1 or 0 . It tests for attention

\section{Mini-Mental State Examination}

(MMSE) (Folstein et al., 1975)

The MMSE is a fully structured scale that consists of 30 points grouped into seven categories: orientation to place (state, county, town, hospital, and floor), orientation to time (year, season, month, day, and date), registration (immediately repeating three words), attention and concentration (serially substracting 7 , beginning with 100 , or, alternatively, spelling the word world backward), recall (recalling the previously repeated three words), language (naming two items, repeating a phrase, reading aloud and understanding a sentence, writing a sentence, and following a three-step command), and visual construction (copying a design). The tests takes 10 minutes. The total score was 30 for educated persons and score of 24 is taken as a cutoff point to diagnose cognitive impairment. The aim of the MMSE in this study was to assess the validity of using the test for screening of cognitive dysfunction resulting from occupational exposure to hydrogen sulfide.

\section{Measurement of ambient H2S concen- tration}

First, it should be noted that at the time of performing the environmental study, 
there was no noticeable obstructions in any of sewer networks in the previously mentioned regions. Measurement of the ambient hydrogen sulfide was done in 5 areas; inside manhole opening at a depth of 50 centimeter ( 2 sewers in Kasr El Aini hospitals), around the openings of the 2 sewers within a circle of a circumference of $0.5-1$ $\mathrm{m}$, and a control area.

Collection of hydrogen sulfide gas was accomplished by utilizing the absorption method described by Harrison and Perry (1986).

\section{Statistical Analysis:}

Results were evaluated for each group. Data were compared using Student's t-test. Qualitative data were compared using chi square test. ANOVA test was used to compare exposed subgroups and control subjects. Pearson correlation test was used to test the correlation between different variables among the exposed groups. The statistical significance was defined as $\mathrm{P}$ value $<0.05$. Computer based statistical package for social sciences (SPSS) for windows 9.1 program was used.

\section{Results:}

The mean concentration of $\mathrm{H} 2 \mathrm{~S}$ in the air samples drawn from the inside of manhole opening was $13.2 \mathrm{mg} / \mathrm{m}^{3}$ (9.4 ppm) with a range $\left(12.2 \mathrm{mg} / \mathrm{m}^{3}-14.6 \mathrm{mg} / \mathrm{m}^{3}\right.$ i.e (8.8 ppm - $10.5 \mathrm{ppm})$. There was only sample in which the H2S concentration exceeded the Permissible Exposure Limit (PEL) established by the Occupational Safety and Health Administration (OSHA) and the American Conference of Governmental Industrial Hygienists (ACGIH) (14 $\mathrm{mg} / \mathrm{m} 3$ i.e $10 \mathrm{ppm}$ ). Unsurprisingly, much lower concentration were found in the air samples drawn from the area around the sewer openings with mean concentration of $6.9 \mathrm{mg} / \mathrm{m}^{3}$ ( $\left.4.8 \mathrm{ppm}\right) \quad($ range $=7.5-$ $9.2 \mathrm{mg} / \mathrm{m}^{3}$ (5 - $\left.6.6 \mathrm{ppm}\right)$. The control area showed nil concentration.

This study was conducted among 63 males divided into an exposed sewer network maintenance workers $(n=33)$ and a matched control group $(n=30)$. The age range of the individuals in the exposed group was (28-57 years) with a mean value of $47.36 \pm 8.23$ years showing no statistically significant difference when compared with the control group (range $=25-56$ years, mean $=44.18 \pm 9.09)$. The mean duration of working years of the exposed personnel was $17.9 \pm 6.68$ years ( range $=5-27$ years).

As regards neurological symptoms suggestive of cognitive dysfunction (headache, memory defects and lack of concentrations), statistically significant higher frequencies were found among the exposed group compared to their controls ( table, 1) 
$(\mathrm{P}<0.5)$. Clinical, physical and neurologic examinations were unremarkable.

Neurophysiological testing showed significantly prolonged mean values of P300 latency $($ range $=432-614 \mathrm{~m} \mathrm{sec}$ ) and simple reaction time (range $=296-438 \mathrm{~m} \mathrm{sec}$ ) in exposed subjects compared to their controls $(\mathrm{P}<0.001)($ table, 2) with no significant difference between the two examined groups regarding the $\mathrm{P} 300$ amplitude (data not presented). It is worth noting that, there were 6 exposed workers (18\%) whose P300 latency exceeded $500 \mathrm{~m}$ sec. As regards neuopsychological testing, the sewer workers showed poor performance in most of Wechsler Memory Scale-revised subtests. Apart from the figural memory subtest, the mean scores of the other subtests (visual paired associates I, visual reproduction I and logical memory) were lower among the exposed subjects $($ table,2) $(\mathrm{P}<0.01)$. Among the exposed subjects, there were 3 $(9.5 \%)$ workers had scored $<25$ in logic memory test

Qualitative analysis of the results of digit forwards and backwards revealed significant statistical difference between exposed and control groups as regards number of subjects having impaired and defective scores $(\mathrm{P}<0.05$ table 3$)$
Verbal fluency and Trail making A test were used as indicators for frontal executive functions. Scores of verbal fluency in the exposed workers were significantly lower than the controls ( table 2) $(\mathrm{P}<0.001)$. Besides, there were 20 out of the 33 exposed workers scored $<15$ words ( $80 \%$ ) versus only 1 out of the control subjects (3.33\%). Out of the 20 workers scoring $<15$ words, there were 6 workers who scored $<10$.

As regards, trail making $\mathrm{A}$ test, ( $\mathrm{a}$ qualitative test for attention) 15 exposed subjects $(23.8 \%)$ failed to perform this test while all control subjects performed this test successfully.

Estimation of urinary thiosulfate as an index of hydrogen sulfide exposure, showed marked increase of its concentration among the exposed workers compared to their controls ( table $2 \mathrm{P}<0.001$ ). However this increase was not correlated with any of the applied neurophysiological, neuropsychological tests or the duration of work $(\mathrm{P}>0.05)$ (data are not presented).

Taking into consideration the educational level and age during assessment of MMSE test among the study groups, 29- 30 was considered the expected normal score. However, although none of the exposed workers scored $\leq 24$ which is considered 
a cutoff point for diagnosis of profound cognitive dysfunction, sewer workers had significantly lower mean score than their controls $(\mathrm{P}<0.001)$ (table 2). A statistically significant correlation was found between MMSE and P300 latency $(r=-.412, \mathrm{P}<0.05)$ (figure 1). Moreover, simple reaction time and logic memory subtest were negatively correlated with MMSE but without significance $(r=-0.04,-0.138$ respectively, $\mathrm{P}>0.05$ ). The exposed group was subdivided according to MMSE score into 2 groups, the first included those with MMSE score $>27(\mathrm{n}=9)$ and the second group included those with MMSE score $\leq 27$. Analysis of variance (ANOVA) test between the exposed subgroups and the controls revealed significantly lower mean values of most scores among the exposed group scoring $\leq$ 27 ( table 4). Regarding trail making A test, there were 3 out of 9 workers with MMSE score $>27$ failed to perform the test versus 12 out of 24 scoring $\leq 27$.

Table (1): Frequency distribution of neurological symptoms among both H2S exposed ( $n=33$ ) and control $(n=30)$ groups as detected from the clinical history

\begin{tabular}{|l|c|c|c|c|c|}
\hline \multirow{2}{*}{ Symptoms } & \multicolumn{2}{|c|}{$\begin{array}{c}\text { Exposed } \\
\mathrm{N}=33\end{array}$} & \multicolumn{2}{c|}{$\begin{array}{c}\text { Control } \\
\mathrm{N}=30\end{array}$} & \multirow{2}{*}{$\mathrm{P}$} \\
\cline { 2 - 5 } & $\mathrm{N}$ & $\%$ & $\mathrm{~N}$ & $\%$ & \\
\hline Headache & 12 & 36.36 & 7 & 23.3 & $>0.05$ \\
\hline Memory defect & 12 & 36 & 3 & 10 & $<0.01^{*}$ \\
\hline Lack of concentration & 14 & 24.4 & 3 & 10 & $<0.01^{*}$ \\
\hline
\end{tabular}

*statistically significant $\mathrm{P}<0.01$ 
Table (2): Mean \pm SD of the results of neurophysiological tests and neuropsychological tests, Mini Mental State Examination test (MMSE) and urinary thiosulfate ( $\mu \mathrm{mol} / \mathrm{mg}$ creatinine) in both control and exposed groups.

\begin{tabular}{|l|c|c|c|}
\hline & $\begin{array}{c}\text { Exposed } \\
\mathrm{N}=33\end{array}$ & $\begin{array}{c}\text { Control } \\
\mathrm{N}=30\end{array}$ & $\mathrm{P}$ \\
\hline Neurophsiological tests & $380.45 \pm 41.43$ & $342.67 \pm 31.51$ & $<0.001^{*}$ \\
P300 latency & $487.32 \pm 45.22$ & $299.14 \pm 20.02$ & $<0.001^{*}$ \\
Simple R T & & & \\
\hline Neuropsychological tests & $9 \pm 1.36$ & $8.63 \pm 1.5$ & $>0.05$ \\
Figural memory & $9 \pm 1.36$ & $10.73 \pm 0.98$ & $<0.001^{*}$ \\
Visual paired & $2.55 \pm 0.9$ & $3.9 \pm 0.48$ & $<0.001^{*}$ \\
Visual reproduction & $29.91 \pm 4$ & $32.33 \pm 2$ & $<0.05^{*}$ \\
Logic memory & $11.82 \pm 2.55$ & $16.23 \pm 1.38$ & $<0.001^{*}$ \\
Verbal fluency & & & $<0.001^{*}$ \\
& $27.33 \pm 1.1$ & $30.0 \pm 0$ & $<0.001^{*}$ \\
\hline MMSE & $50.618 \pm 8.95$ & $25.12 \pm 5.07$ & \\
\hline
\end{tabular}

*statistically significant.

Table 3: Frequency distribution of performance of digit forwards and digit backwards span subtests among $\mathrm{H} 2 \mathrm{~S}$ exposed $(n=33)$ and control $(n=30)$ groups.

\begin{tabular}{|c|c|c|c|c|c|c|c|c|c|c|c|c|c|}
\hline & \multicolumn{4}{|c|}{ Normal $^{1}$} & \multicolumn{4}{|c|}{ Impaired $^{2}$} & \multicolumn{4}{|c|}{ Defective $^{3}$} & \multirow{3}{*}{$\mathrm{P}$} \\
\hline & \multicolumn{2}{|c|}{ Exposed } & \multicolumn{2}{|c|}{ control } & \multicolumn{2}{|c|}{ exposed } & \multicolumn{2}{|c|}{ control } & \multicolumn{2}{|c|}{ exposed } & \multicolumn{2}{|c|}{ control } & \\
\hline & no & $\%$ & no & $\%$ & no & $\%$ & no & $\%$ & no & $\%$ & no & $\%$ & \\
\hline Digit forward & 18 & 54.5 & 30 & 100 & 12 & 36.3 & 0 & 0 & 3 & 9 & 0 & 0 & $<0.05$ \\
\hline Digit backward & 9 & 27.2 & 27 & 90 & 15 & 45.4 & 3 & 10 & 9 & 27.2 & 0 & 0 & $<0.05$ \\
\hline
\end{tabular}

Normal $^{1}$ score of digit forwards is $6 \pm 1 \quad$ Normal $^{1}$ score of digit backwards is $5 \pm 1$

Impaired ${ }^{2}$ score of digit forwards is $4 \quad$ Impaired $^{2}$ score of digit backwards is 3

Defective $^{3}$ score of digit forwards is 3 Defective ${ }^{3}$ score of digit backwards is 2 
Table (4): Mean \pm SD of the results of neurophysiological tests neuropsychological tests in exposed subgroups ( MMSE score $>27\{n=9\}$ and MMSE score $\leq 27\{n=24\}$ ) and control group $(\mathbf{n}=30)$.

\begin{tabular}{|c|c|c|c|c|}
\hline & $\begin{array}{c}\text { Exposed group } \\
\text { MMSE } \leq 27 \\
\mathrm{~N}=24\end{array}$ & $\begin{array}{c}\text { Exposed group } \\
\text { MMSE }>27 \\
\mathrm{~N}=9\end{array}$ & $\begin{array}{c}\text { Control } \\
\text { MMSE=30 } \\
\mathrm{N}=30\end{array}$ & $\mathrm{P}$ \\
\hline $\begin{array}{c}\text { Neurophysiological } \\
\text { P300 latency }\end{array}$ & $498.53 \pm 46.73$ & $457.53 \pm 22.99$ & $299.14 \pm 20.02$ & $<0.001^{*}$ \\
\hline R T & $383.12 \pm 45.66$ & $373.33 \pm 28.16$ & $342.6 \pm 31.51$ & $<0.001^{*}$ \\
\hline $\begin{array}{c}\text { Neurosychological } \\
\text { Visual paired }\end{array}$ & $8.75 \pm 1.51$ & $9.67 \pm 0.5$ & $10.73 \pm 0.98$ & $<0.001^{*}$ \\
\hline Visual reproduction & $2.75 \pm 0.84$ & $2.0 \pm 0.86$ & $3.83 \pm 0.46$ & $<0.001^{*}$ \\
\hline Logic memory & $27.62 \pm 2.79$ & $32.76 \pm 4.09$ & $32.7 \pm 2.03$ & $<0.001^{*}$ \\
\hline Verbal fluency & $11.88 \pm 2.9$ & $12 \pm 1.73$ & $16.23 \pm 1.38$ & $<0.001^{*}$ \\
\hline
\end{tabular}

*statistically significant

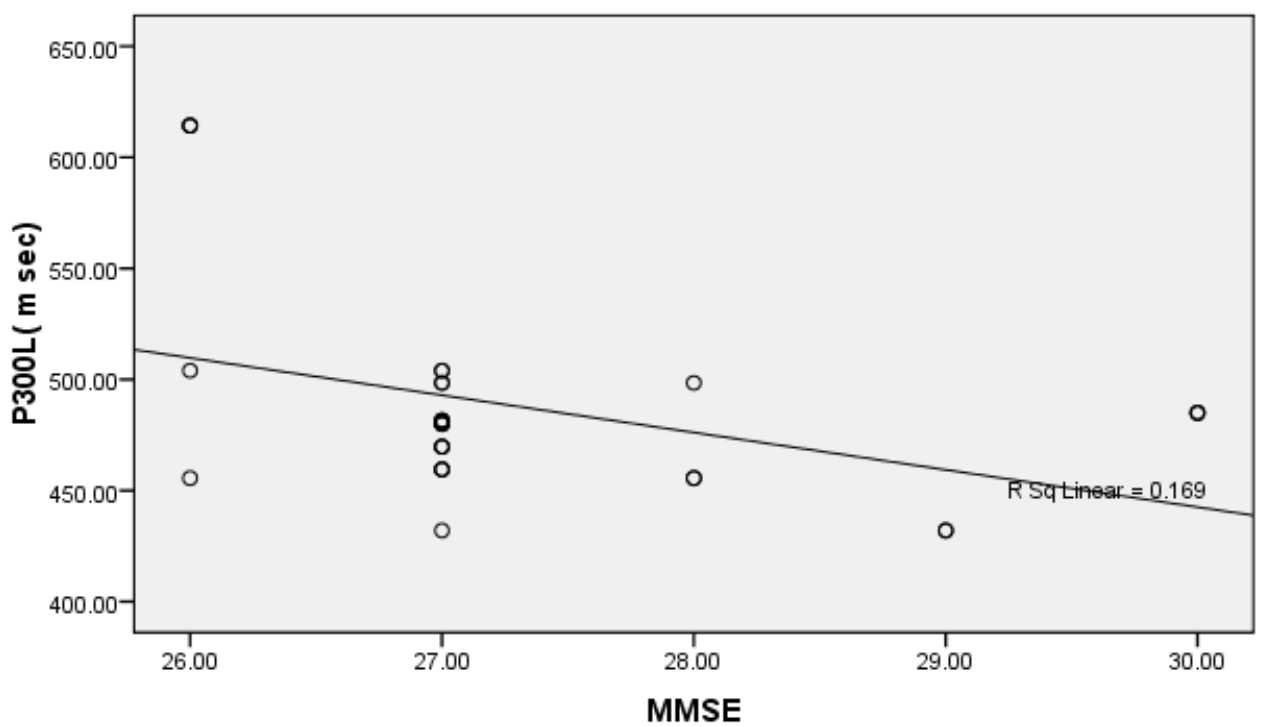

Figure 1: Significant negative correlation between MMSE score and P300 latency among sewer network workers $(n=33)(r=-.412)(P=0.017)$. 


\section{Discussion:}

This study shows cognitive functions impairment among sewer network workers as revealed from the prolonged simple reaction time and P300 latency besides the poor performance in neuropsychological tests applied in this study. Although urinary thiosulfate concentration is elevated among the exposed workers, it is not correlated with results of any of the applied neurophysiological or neuropsychological subtests. This indicates that thiosulfate can be considered only as exposure marker but it cannot be used as screening test of cognitive impairment resulting from $\mathrm{H} 2 \mathrm{~S}$ exposure. Moreover, exposed workers having MMSE score $<28$ show significantly lower mean values in most of the applied tests pointing to the possibility of using MMSE as a rapid screening test for cognitive impairment with taking 27 as a cutoff point.

Sewer network workers are exposed to multitudes of serious chemical and biological hazards. One of these serious chemical hazards is occasional exposure to high concentrations of $\mathrm{H} 2 \mathrm{~S}$ in the sewer pipes (wild et al., 2006). However, exposure to $\mathrm{H} 2 \mathrm{~S}$ among sewer workers is not limited to fatal concentrations, but lower dose exposure is encountered during their routine work of inspection and maintenance of the sewer networks especially in frequently opened pipes.
In this study, although environmental measurement of ambient concentration of $\mathrm{H} 2 \mathrm{~S}$ showed levels that did not exceed the recommended levels stated by OSHA and ACGIH $(10 \mathrm{mg} / \mathrm{m} 3$ or 10ppm) except in one occasion, we cannot exclude the occurrence of higher concentrations especially during obstruction and subsequent stagnation of sewage. However, WATCH (Working Group on the Assessment of Toxic Chemicals) in UK, suggested $5 \mathrm{ppm}$ to the occupational exposure limit (OEL) for $\mathrm{H} 2 \mathrm{~S}$. The recommendation to review the OELs for $\mathrm{H} 2 \mathrm{~S}$ is because in the mid 1990s a series of human volunteer studies were published that suggested exposures as low as $10 \mathrm{ppm}$ might cause a shift to anaerobic metabolism under conditions of physical exertion. This leads to a concern for adverse physiological effects at the existing occupational exposure standard (OES) values for $\mathrm{H} 2 \mathrm{~S}$ of $10 \mathrm{ppm}$ ( 8 hour time weighted average (TWA) (Costigen, 2003).

Mild cognitive impairment has been described as transitional state between normal aging and dementia . It is mainly focused on working memory, conceptual reasoning, speed of information processing, attention and executive function ( peteresen et al.,2001). In the current study, investigating the frequency of some of central nervous system symptoms that may suggest 
cognitive impairment ( memory defects, and lack of concentration), revealed statistically significant higher percentage of these symptoms among the exposed group compared to the controls ( table $1, \mathrm{P}<0.01$ ). These results are greatly supported by a similar study of Thorn et al., (2002) who reported significantly increased risks for similar symptoms among sweden sewage workers. Also similar symptoms were reported among ex-workers and neighboring residents who were exposed to hydrogen sulfide and other reduced-sulfur compounds emitted from an oil refinery in concentrations ranged from a low of $10 \mathrm{ppb}$ to 8.8 ppm (Kilburn et al.,1995 ; Legator et al., 2001).

However, surveys and studies of subjective reported symptoms may be susceptible to response enhancement bias (i.e., an increase in reported symptoms resulting from the fact that respondents are aware of, and sensitized to, the fact that they are exposed). Therefore, modern neurobehavioral methods are used in the assessment of the early effects due to exposure to neurotoxic agents in working and general environment (Albini and Benedetti, 2004).

Cognitive event-related potentials (ERPs) have been widely used in the study of dementive disorders, including Alzheimer's disease. Of the major waves observed in the ERPs (N200, P300 and Slow Wave), P300 component corresponds to mental processes such as recognition, categorization of stimuli, expectancy or short-term memory while there are many regions in the brain, especially in the temporal lobe, the parietal lobe and the hippocampus which are thought to be responsible for its generation (Bennys et al.,2007).

The numerous clinical P300 studies strongly suggest that this ERP component, elicited by auditory, visual, olfactory or somatosensory stimuli, may be clinically useful as an index of cognitive function (Papaliagkas et al.,2008). In our study there was a significant delay in P300 latency among sewer workers versus their controls (487.32 \pm 45.22 , 299.14 $\pm 20.02 \mathrm{~m} \mathrm{sec}$ respectively, $\mathrm{P}<0.001$ ) besides there were 6 exposed workers having abnormally prolonged P300 latency pointing to the possibility of cognitive impairment. This goes in accordance with Hirsch's study in (2002) that reported delayed P300 latency as residual chronic effect after hydrogen sulfide intoxication without loss of consciousness. Unsurprisingly, delayed P300 latency was accompanied with delayed simple reaction time which is greatly supported by the study of Kilburn (2003) who reported prolonged simple reaction time among $43 \%$ of chronically exposed workers to moderate doses of hydrogen sulfide. 
Currently, one of the most important tools when assessing early cognitive impairment is neuropsychological evaluation where mild cognitive impairment subjects typically record neuropsychological performance between that of healthy older individuals and demented patients (ArnÃ $\tilde{A}_{i z}$ and Almkvist, 2003). In our study, most of the examined subjects showed poor performance of tests assessing attention and short term memory. Besides, the executive functions were found to be impaired in a large percentage of the exposed workers who failed to perform the trail A making test ( $23.8 \%$ ) and those who scored $<15$ $(80 \%)$ in verbal fluency test. Comparable findings were reported in previous studies that applied similar neuropsychological tests investigations among occupationally and residentially exposed personnel (Kilburn et al., 1995, Kilburn,1997; Legator et al., 2001;Kilburn, 2003)

The current mechanistic understanding of hydrogen sulfide toxicity is incomplete and the patho-physiological mechanisms underlying the effect of $\mathrm{H} 2 \mathrm{~S}$ on normal brain function, particularly, following chronic exposure have yet to be identified ( ATSDR,2004 ). The toxicity of H2S has been attributed to its ability to inhibit cytochrome oxidase in a similar manner to $\mathrm{HCN}$ but recently, it is hypothesized that
$\mathrm{H} 2 \mathrm{~S}$ can reduce intracellular bound ferric iron to form unbound ferrous iron, which activates iron. Additionally, $\mathrm{H} 2 \mathrm{~S}$ can increase the hepatocyte formation of reactive oxygen species (ROS). H2S cytotoxicity therefore also involves a reactive sulfur species, which depletes glutathione (GSH) and activates oxygen to form ROS (Truong et al., 2006). However, it is suggested that, neurobehavioral effects following longterm exposure is accumulative. That is each exposure results in increased brain damage. The individual damage does not recover, and brain dysfunction continues for years (Kilburn, 2004).

A study of ultrastructural and morphometric characteristics of nerve cells and myelinated fibers in the cerebral cortex, revealed activation of protein synthesis in nerve cells after chronic exposure to natural hydrogen sulfide-containing gas in low concentrations $(10 \mathrm{mg} / \mathrm{m} 3)$ for 2 weeks. After 1 month, the ultra-structure of myelinated fibers was characterized by sectorial loosening and demyelination (Solnyshkova and Shakhlamov, 2002).

What adds to the complexity of hydrogen sulfide toxicity, is the existence of a functional genetic polymorphism affecting rhodanese or thiosulfate sulfurtransferase (TST) activity. (TST) is a mitochondrial matrix enzyme that plays roles in the for- 
mation of iron-sulfur proteins, the modification of sulfur-containing enzymes, and is also involved in $\mathrm{H} 2 \mathrm{~S}$ detoxification thus playing role in the individual susceptibility to hydrogen sulfide neurotoxicity (BillautLaden et al., 2006).

Regarding urinary thiosulfate, the study revealed remarkable increase of its concentrations among the exposed workers compared to their controls (Table $2 \mathrm{P}<0.001$ ). This goes in accordance with the study of Kage et al., (1997) when the authors obtained concentrations of urinary thiosulfate 4- 14 times higher among hydrogen sulfide exposed workers than the controls. It worth noting that, $\mathrm{H} 2 \mathrm{~S}$ does not accumulate in the body and the urinary thiosulfate levels peak approximately 15 hours after exposure and drop to control levels by 17 h post-exposure (Milby and Baselt,1999). Therefore, the increased concentrations of urinary thiosulfate indicates the continuous daily occupational exposure to hydrogen sulfide among our exposed workers. However, a quantitative relationship between hydrogen sulfide exposure levels and urinary thiosulfate levels has not been established in many studies ( ATSDR, 2004) and this explains the insignificant correlation between the duration of exposure and the concentration level of urinary thiosulfate $(\mathrm{P}>0.05)$. This fact along with absence of statistically significant correlation between the urinary thiosulfate with any of neurophysiological and neuropsycological parameters used in this study, limit the ability of this biomarker to be an estimate of a threshold level above which exposure is to be stopped.

In the current study, MMSE advantages of brevity and ease of administration were applied to verify its use as a screening test for cognitive dysfunction among workers occupationally exposed to hydrogen sulfide gas. The significant decrement in the mean value of MMSE scoring in the exposed group $(27.33 \pm 1.1)$ versus $(30 \pm 0)$ in the controls was associated with significant negative correlation with P300 latency ( $r=$ -.412, $\mathrm{P}<0.05$ ) ( figure, 1), simple reaction time and logic memory ( $\mathrm{P}>0.05)$. Similar correlations between MMSE scoring and Wechsler Adult intelligence scale and long latency auditory evoked potentials were reported in many previous studies ( Crum et al., 1993).

The MMSE is used to screen patients for cognitive impairment and to date, a score of 24 on the MMSE has commonly been used by clinicians, nurses, psychologists, and others as a cutoff value for dementia evaluation in all patients( Crum et al., 1993). However, although none of the exposed workers scored $\leq 24$, using more comprehensive neurophysiological and neurop- 
sychological assessment of study subjects revealed an evident degree of cognitive impairment particularly among exposed workers having MMSE score <27 ( table 4). This finding is greatly supported by the study of Missonnier et al., (2005). The authors performed extensive neurophysiological and neuropsychological assessment for a group of subjects with MMSE score between 2528 with subsequent follow up after 1 year. Results showed that $54 \%$ of those subjects revealed significant cognitive decline. These finding go in accordance with other studies that suggest taking MMSE score of 27 as cutoff point to perform more specific evaluation and therefore allow earlier diagnosis (O’Bryant et al., 2008).

\section{Conclusion:}

The findings in our study, taken together with previously reported data concerning adverse neurological effects due to chronic exposure to hydrogen sulfide gas, mandate the need for continued research with larger scale studies. This is decided of large sector of subjects occupationally exposed to hydrogen sulfide gas. In addition, our study recommends the use of the ease and brevity of MMSE (it takes only 10 minutes) as a periodic rapid screening test for cognitive dysfunction among exposed workers then performance of more comprehensive study for workers scoring $<27$.

\section{Acknowledgement:}

This study was self funded by the authors who are very grateful to both Prof. Alia Abd Elshakour, head of air pollution unit, National Research Center, Cairo, Egypt and Dr. Laila A. Rashed, Assist. Prof. of Biochemistry Dept. Faculty of Medicine ,Cairo University, Egypt, for their technical help in the estimation of the hydrogen sulfide ambient levels and the urinary thiosulfate .

\section{References:}

1. Agency for Toxic Substances and Disease Registry (ATSDR) 2004: Toxicological profile for hydrogen sulfide (Draft for Public Comment). Atlanta, GA: U.S. Department of Health and Human Services, Atlanta, Georgia.

2. Albini, E. and Benedetti L.2004: Neurobehavioral tests in occupational medicine: diagnosis and prevention. G Ital Med Lav Ergon. 26:251-4.

3. Arn $\tilde{A}_{i} i z$, E. and Almkvist, O. 2003: Neuropsychological features of mild cognitive impairment and preclinical Alzheimer's disease. Acta Neurol Scand Suppl. 179:34-41

4. Bennys, K., Portet, F., Touchon, J., and Rondouin, G. 2007: Diagnostic value of event-related evoked potentials N200 and P300 subcomponents in early diagnosis of Alzheimer's disease and mild cognitive impairment. J Clin Neurophysiol. $24: 405-412$

5. Benton, A. 1968: Differential behavioral effects in frontal lobe disease. Neuropsychologia, 6: 53-60.

6. Billaut-Laden, I., Allorge, D., Crunelle-Thibaut, A., Rat, E., Cauffiez, C., Chevalier, D., et al., 2006: Evidence for a functional genetic poly- 
morphism of the human thiosulfate sulfurtransferase (Rhodanese), a cyanide and $\mathrm{H} 2 \mathrm{~S}$ detoxification enzyme. Toxicology. 225:1-11.

7. Costigan, M. 2003: Hydrogen sulfide: UK occupational exposure limits. Occup Environ Med 60:308-12.

8. Crum, R., Anthony, J., Bassett, S. and Folestein, M. 1993: Population-Based Norms for the MiniMental State Examination by Age and Educational Level. JAMA. 269 (18):2386-2391)

9. Environmental protection agency (EPA) 2003: Toxicological review of hydrogen sulfide (CAS No. 7783-06-4). In Support of Summary Information on the Integrated Risk Information System (IRIS)

10. Fenga, C., Cacciola, A. and Micali, E.2002: Cognitive sequelae of acute hydrogen sulphide poisoning. A case report. Med Lav.;93:322-8.

11. Folstein, M. Folstein, S. and McHugh, P. 1975: "Mini-mental State". A practical method of grading the mental state of patients for the clinicians. Journal of Psychiatry Research, 12: 189198.

12. Harrison, R. and Perry, T. 1986: Handbook of air pollution analysis.2nd ed., Champan and Hall, London.

13. Hirsch, A. 2002: Hydrogen sulfide exposure without loss of consciousness: chronic effects in four cases. Toxicol Ind Health. 18:51-61.

14. Kage, S., Takekawa, K., Kurosaki, K., Imamura, T. and Kudo, K. 1997: The usefulness of thiosulfate as an indicator of hydrogen sulfide poisoning: three cases. Int J Legal Med. 110:220-2.

15. Kilburn, K.1997: Exposure to reduced sulfur gases impairs neurobehavioral function. South Med J. 90:997-1006.

16. Kilburn, K. 2001: Function testing for chemical brain damage: a review. Arch Environ Health. 56:132-7.

17. Kilburn, K. and Warshaw, R. 1995: Neurotoxic Effects from Residential Exposure to Chemicals from an Oil Reprocessing Facility and Super- fund Site. Neurotoxicology and Teratology. 17: 89-102.

18. Kilburn, K. 2003: Effects of Hydrogen Sulfide on Neurobehavioral Function. Southern Medical Journal. 96: 639-646.

19. Kilburn, K. 2004: Endangered Brains: How Chemicals Threaten Our Future. Birmingham, AL: Princeton Scientific Publishers Company, Inc. P:77-81

20. Legator, M., Singleton, C., Morris, D. and Philips, L. 2001: Health Effects from Chronic Low-Level Exposure to Hydrogen Sulfide. Archives of Environmental Health. 56: 123-131.

21. Milby, TH. and Baselt, C. 1999: Hydrogen Sulfide Poisoning: Clarification of Some Controversial Issues. American Journal of Industrial Medicine. 35: 192-195.

22. Missonnier, P., Gold, G., Costa, L., Michel, J., Mulligan, R., Michon, A. et al., 2005: Early event related potential changes during working memory activation predict rapid decline in mild cognitive impairment. J.Gerontology 60 A: $660-666$

23. Niedermeyer, E. and Lopes Da Silva, F. 1999: P300 in Clinical Applications. In: Niedermeyer, E. (1st ed.). Electroencephalography, 4th edition, 1073-1135.

24. O’Bryant, S., Humphreys, J., Smith, G., Ivnik, R., Graff-Randford, N. and Petresen, R. 2008: Detecting dementia with the mini-mental state examination in highly educated individuals. Archives of Neurology. 65: 963--967

25. Papaliagkas, V., Kimiskidis, V., Tsolaki, M. and Anogianakis, G. 2008: Usefulness of eventrelated potentials in the assessment of mild cognitive impairment BMC. Neurosci. 9: 107-115

26. Petersen, R., Doody, R., Kurz, A., Mohs, R., Morris, J., Rabins, P. et al., 2001: Current concepts in mild cognitive impairment. Arch Neurol. $58: 1985-1992$. 
27. Reitan, R. 1958: Validity of the trail making test as an indicator of organic brain damage. Percept. Mot. Skills ,8: 271-276.

28. Saad, A., Ibrahim, Y. and Abdel-Shakour, A. 2003: Respiratory health problems of sewage workers. Egyptian journal of occupational medicine 27 :201-228.

29. Solnyshkova, T. and Shakhlamov, V. 2002: Ultrastructural and morphometric characteristics of nerve cells and myelinated fibers in the cerebral cortex after chronic exposure to natural gas containing hydrogen sulfide in low concentrations. Bull Exp Biol Med. 134:411-3.

30. Sorbo, B. and Ohman, T. 1978: Determination of thiosulfate in urine. Scand. J. Clin. Lab. Inves. 38 6: 521-7

31. Thompson, R., Valentine, H. and Valentine, W. 2003: Cytotoxic mechanisms of hydrosulfide anion and cyanide anion in primary rat hepatocyte cultures. Toxicology.188:149-59.
32. Thorn, J., Beijer, L. and Rylander, R. 2002: Work related symptoms among sewage workers: a nationwide survey in Sweden. Occupational and Environmental Medicine. 59:562-566

33. Truong Don, H., Eghbal, M., Hindmarsh, W., Roth, H. and O'Brien, J. 2006: molecular mechanism of hydrogen sulfide toxicity. Drug Metabolism Reviews 38:733-744

34. Wechsler, D. 1981: Wechsler Adult Intelligence Scale-Revised (WAIS-R), New York, Psychological Cooperation.

35. Wild, P., Ambroise, D., Benbrik, E., Tiberguent, A. and Massin, N. 2006: Mortality among Paris sewage workers. Occup. and Environ. Med.63 :168-172.

36. Yalamanchili, C. and Smith, M. 2008: Acute hydrogen gas toxicity due to sewer gas exposure. Am J Emerg Med.26: 518.e 5-7. 